REFERENCE:

[1] Takeuchi T, et al. Ann Rheum Dis 2016; 75: 1057-64

Acknowledgement: This study was sponsored by Astellas Pharma, Inc. Medical writing support was provided by Rhian Harper Owen of Cello Health MedErgy and funded by Astellas Pharma, Inc.

Disclosure of Interests: Tsutomu Takeuchi Grant/research support from: Astellas Pharma Inc, Chugai Pharmaceutical Co, Ltd., Daiichi Sankyo Co., Ltd., Takeda Pharmaceutical Co., Ltd., AbbVie GK, Asahikasei Pharma Corp., Mitsubishi Tanabe Pharma Co., Pfizer Japan Inc., Eisai Co., Ltd., AYUMI Pharmaceutical Corporation, Nipponkayaku Co. Ltd., Novartis Pharma K.K., Grant/research support from: AbbVie, Asahi Kasei, Astellas, AstraZeneca, AYUMI, Bristol-Myers Squibb, Chugai, Daiichi Sankyo, Eisai, Eli Lilly Japan, Janssen, Mitsubishi Tanabe, Nippon Kayaku, Novartis, Pfizer Japan Inc, Taiho, Taisho Toyama, Takeda, Teijin, Grant/ research support from: Astellas Pharma Inc., Bristol Myers Squibb, Chugai Pharmaceutical Co., Ltd., Mitsubishi Tanabe Pharma Co., Pfizer Japan Inc., Santen Pharmaceutical Co., Ltd., Takeda Pharmaceutical Co., Ltd., Teijin Pharma Ltd., AbbVie GK, Asahi Kasei Pharma Corp., Taisho Toyama Pharmaceutical Co., Ltd. SymBio Pharmaceuticals Ltd., Janssen Pharmaceutical K.K., Celltrion Inc., Nipponkayaku Co. Ltd., and UCB Japan, Consultant for: Astra Zeneca K.K., Eli Lilly Japan K.K., Novartis Pharma K.K., Mitsubishi Tanabe Pharma Co., Abbivie GK, Nipponkayaku Co.Ltd, Janssen Pharmaceutical K.K., Astellas Pharma Inc., Taiho Pharmaceutical Co. Ltd., Chugai Pharmaceutical Co. Ltd., Taisho Toyama Pharmaceutical Co. Ltd., GlaxoSmithKline K.K., UCB Japan Co. Ltd., Consultant for: AbbVie, Asahi Kasei, Astellas, AstraZeneca, AYUMI, Bristol-Myers Squibb, Chugai, Daiichi Sankyo, Eisai, Eli Lilly Japan, Janssen, Mitsubishi Tanabe, Nippon Kayaku, Novartis, Pfizer Japan Inc, Taiho, Taisho Toyama, Takeda, Teijin, Consultant for: Astra Zeneca K.K., Eli Lilly Japan K.K., Novartis Pharma K.K., Mitsubishi Tanabe Pharma Co., Asahi Kasei Medical K.K., AbbVie GK, Daiichi Sankyo Co., Ltd., Bristol Myers Squibb, and Nipponkayaku Co. Ltd., Speakers bureau: Astellas Pharma Inc., Bristol Myers Squibb, Chugai Pharmaceutical Co., Ltd., Mitsubishi Tanabe Pharma Co., Pfizer Japan Inc., Santen Pharmaceutical Co., Ltd., Takeda Pharmaceutical Co., Ltd., Teijin Pharma Ltd., AbbVie GK, Asahi Kasei Pharma Corp., Taisho Toyama Pharmaceutical Co., Ltd., SymBio Pharmaceuticals Ltd., Janssen Pharmaceutical K.K., Celltrion Inc., Nipponkayaku Co. Ltd., and UCB Japan, Speakers bureau: AbbVie, Asahi Kasei, Astellas, AstraZeneca, AYUMI, Bristol-Myers Squibb, Chugai, Daiichi Sankyo, Eisai, Eli Lilly Japan, Janssen, Mitsubishi Tanabe, Nippon Kayaku, Novartis, Pfizer Japan Inc, Taiho, Taisho Toyama, Takeda, Teijin, Speakers bureau: AbbVie GK., Bristol-Myers K.K., Chugai Pharmaceutical Co. Ltd., Mitsubishi Tanabe Pharma Co., Pfizer Japan Inc., Astellas Pharma Inc, Diaichi Sankyo Co. Ltd., Eisai Co. Ltd., Sanofi K.K., Teijin Pharma Ltd., Takeda Pharmaceutical Co. Ltd., Novartis Pharma K.K., Yoshiya Tanaka Grant/research support from: Abbvie, Astellas, Bristol-Myers Squibb, Chugai, Daiichi-Sankyo, Eisai, Mitsubishi-Tanabe, MSD, Ono, TaishoToyama, Takeda, Speakers bureau: Abbvie, Asahi-kasei, Astellas, Bristol-Myers Squibb, Chugai, Daiichi-Sankyo, Eli Lilly, Eisai, Glaxo-Smithkline, Janssen, Mitsubishi-Tanabe, Novartis, Pfizer Japan Inc, Sanofi, Takeda, UCB, YL Biologics, Sakae Tanaka Grant/research support from: KYOCERA Corporation and Asahi Kasei Corporation, Consultant for: Amgen Astellas BioPharma K.K., KYOCERA Corporation, Pfizer and Daiichi Sankyo Co., Ltd., Speakers bureau: Asahi Kasei Corporation, Astellas Pharma Inc, Ayumi Pharmaceutical Corporation, Eisai Co., Ltd., Ono Pharmaceutical Co., Ltd., Daiichi Sankyo Co., Ltd, Taisho Toyama Pharmaceutical Co., Ltd., Mitsubishi Tanabe pharma Corporation, Chugai Pharmaceutical Co., Ltd., Teijin Pharma Ltd., Eli Lilly, Hisamitsu Pharmaceutical Co, Inc., Pfizer, Bristol-Myers., Atsushi Kawakami Grant/research support from: Astellas Pharma, Consultant for: Astellas Pharma, Speakers bureau: Astellas Pharma, Manabu Iwasaki: None declared, Mitsuhiro Rokuda Employee of: Astellas Pharma, Inc., Hiroyuki Izutsu Employee of: Astellas Pharma, Inc., Satoshi Ushijima Employee of: Astellas Pharma, Inc., Yuichiro Kaneko Employee of: Astellas Pharma, Inc., Teruaki Shiomi Employee of: Astellas Pharma, Inc., Emi Yamada Employee of: Astellas Pharma, Inc. DOI: 10.1136/annrheumdis-2019-eular.1580

\section{OP0027 \\ EFFECT OF SHORT-TERM METHOTREXATE DISCONTINUATION ON THE DISEASE ACTIVITY IN PATIENTS WITH RHEUMATOID ARTHRITIS: POSTHOC-ANALYSIS OF TWO RANDOMIZED CLINICAL TRIALS}

Min Jung Kim, Yeong Wook Song, Eun Bong Lee, Jin Kyun Park. Seoul National University Hospital, Seoul, Division of Rheumatology, Department of Internal Medicine, Seoul, Korea, Rep. of (South Korea)

Background: Patients with rheumatoid arthritis (RA) require a continuous, potentially life-long immune suppression with disease modifying antirheumatic drugs (DMARDs) including methotrexate (MTX). However, in special circumstances such as life-threatening infections, vaccinations or major surgeries, use of MTX should be minimized to restore the treatment-associated immune suppression. While a long-term or permanent discontinuation of MTX is associated with a disease flare or relapse, the effect of short-term discontinuation on disease activity has not been fully elucidated.

Objectives: To investigate the effect of short-term discontinuation of MTX on the disease activity in patients with RA on stable dose of MTX.

Methods: This is a posthoc analysis of 2 randomized controlled studies investigating effect of MTX discontinuation for 2 weeks or 4 weeks on vaccine response to seasonal influenza vaccination in patients with RA. In the 4-week discontinuation study, 54 patients continued MTX and 44 patients discontinued it for 4 weeks before vaccination with trivalent seasonal influenza vaccine. In the 2 -week discontinuation study, 159 patients continued MTX and 161 patients held it for 2 weeks after a seasonal quadrivalent influenza vaccine. Disease activity (DAS28 change, DAS28 flare rate and flare-free survival) was compared between the patients who continued MTX and those held it. A RA flare was defined as an increase in DAS28 of $>1.2$ or $>0.6$ if the baseline DAS28 was $\geq 3.2$.

Results: In the 4-week MTX-hold group, the mean DAS28 increased at the 4 weeks after MTX discontinuation by $0.38 \pm 0.94$ and then improved back to baseline after reintroduction of MTX, whereas the mean DAS28 in the MTX-continue group remained stable over time (Figure $1 \mathrm{~A}$ ). The overall flare-free survival during 20 weeks did not differ between the groups (log rank $p=0.142)$ (Figure 1B). However numerically more patients in the MTX-hold group experienced a flare than those in the MTX-continue group during the 4-weeks MTX discontinuation ( $20.5 \%$ vs. $7.4 \%$, $p=0.058$ ). After resuming MTX, the flare rate did not differ between the groups up to 20 weeks of observations (Figure $1 \mathrm{C}$ ). A temporary MTX discontinuation for 2 weeks was not associated with any clinically meaningful change in disease activity.

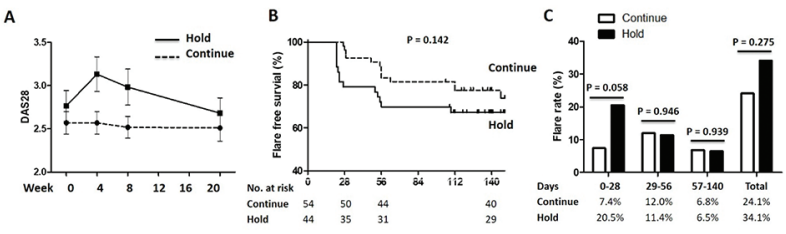

Figure 1. Changes in disease activity of rheumatoid arthritis after MTX discontinuation over time. (A) DAS28-CRP and (B) RA flare free survival in the MTX continue and the MTX hold group were depicted. (C) RA flare rates over time were shown. MTX, methotrexate.

Conclusion: A short-term MTX discontinuation for 2 weeks is safe without any change in disease activity. A 4-week MTX discontinuation is associated with transient increase in disease activity without affecting long-term outcomes.

\section{REFERENCES:}

[1] Park JK, Lee MA, Lee EY, Song YW, Choi Y, Winthrop KL, et al. Effect of methotrexate discontinuation on efficacy of seasonal influenza vaccination in patients with rheumatoid arthritis: a randomised clinical trial. Ann Rheum Dis. 2017 May 03.

[2] Park JK, Lee YJ, Shin K, Ha YJ, Lee EY, Song YW, et al. Impact of temporary methotrexate discontinuation for 2 weeks on immunogenicity of seasonal influenza vaccination in patients with rheumatoid arthritis: a randomised clinical trial. Ann Rheum Dis. 2018 Jun; 77(6):898-904.

[3] Haschka J, Englbrecht M, Hueber AJ, Manger B, Kleyer A, Reiser M, et al Relapse rates in patients with rheumatoid arthritis in stable remission tapering or stopping antirheumatic therapy: interim results from the prospective randomised controlled RETRO study. Ann Rheum Dis. 2016 Jan; 75(1):45-51.

Disclosure of Interests: None declared

DOI: 10.1136/annrheumdis-2019-eular.2524

\section{OP0028 \\ POST-APPROVAL COMPARATIVE SAFETY STUDY OF TOFACITINIB AND BIOLOGIC DMARDS: FIVE-YEAR RESULTS FROM A US-BASED RHEUMATOID ARTHRITIS REGISTRY}

Joel Kremer ${ }^{1}$, Clifton Bingham ${ }^{2}$, Laura Cappelli ${ }^{2}$, Carol Etzel $^{3}$, Jeffrey Greenberg ${ }^{3}$, Jamie Geier ${ }^{4}$, Ann Madsen ${ }^{4}$, Connie Chen ${ }^{4}$, Alina Onofrei ${ }^{3}$, Christine Barr ${ }^{3}$, Dimitrios A. Pappas ${ }^{5}$, Heather J. Litman ${ }^{3}$, Kimberly J. Dandreo ${ }^{3}$, Andrea Shapiro ${ }^{6}$, Carol A. Connell ${ }^{7}$, Arthur Kavanaugh ${ }^{8}$. ${ }^{1}$ Albany Medical College, Center for Rheumatology, Albany, NY, United States of America; ${ }^{2}$ Johns Hopkins University, Baltimore, MD, United States of America; ${ }^{3}$ Corrona, LLC, Waltham, MA, United States of America; ${ }^{4}$ Pfizer Inc, New York, NY, United States of America; ${ }^{5}$ Colombia University, Department of Medicine, New York, NY, United States of America; ${ }^{6}$ Pfizer Inc, Peapack, NJ, United States of America; ${ }^{7}$ Pfizer Inc, Groton, CT, United States of America; ${ }^{8}$ University of California, San Diego School of Medicine, La Jolla, San Diego, CA, United States of America

Background: Tofacitinib is an oral JAK inhibitor for the treatment of rheumatoid arthritis (RA). Real-world data (RWD) complement clinical trial data in assessing 